CLINICAL PRACTICE

\title{
A bedside system for clinical grading of parotid gland enlargement
}

\begin{abstract}
M Tshifularo
Prof. Mashudu Tshifularo, MB ChB, MMed (ORL) (Cum Laude), FCS (SA) ORL, is Head of Otorhinolaryngololgy at the School of Medicine, Faculty of Health Sciences, University of Pretoria, South Africa, and the Steve Biko Academic Hospital Complex, Pretoria. He has an interest in innovative medical practice and surgical techniques, endoscopic technology, development of medical devices, and medical education and training.
\end{abstract}

Corresponding author: M Tshifularo (mashudu.tshifularo@up.ac.za, tshifularom@surgeon.co.za)

There are limited data on grading of parotid gland mass, and currently no bedside clinical grading system is available. Parotid enlargement is common in patients with HIV/AIDS, and the size of the gland can change depending on the progression of disease, with or without treatment. This needs to be recorded accurately and communicated properly. A novel system for bedside clinical grading of parotid gland enlargement using a soft tape measure is proposed.

S Afr Med J 2015;105(6):444-445. DOI:10.7196/SAMJ.9404

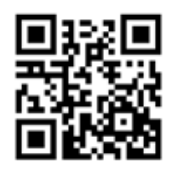

There are limited data on the grading of parotid gland mass, and currently no bedside clinical grading system for benign parotid gland enlargement exists. The TNM (tumour-node-metastasis) clinical staging system is used for malignant tumours of the salivary glands (including the parotid), but not for benign lesions.

Parotid gland enlargement is common among patients with HIV/AIDS. The size of the gland can change depending on disease progression with or without treatment (antiretroviral therapy). A scientific, reliable and cost-effective way to measure parotid gland enlargement is necessary. Such a clinical grading system would be helpful in communicating the degree of parotid gland enlargement to patients and colleagues.

\section{The proposed grading system}

The bedside clinical grading of parotid gland enlargement proposed is based on a study of 100 subjects ( 37 males, 63 females). None had diseases of the parotid gland.

A soft measuring tape was used to measure the estimated surface diameters of the parotid gland in two dimensions, i.e. vertically and obliquely within its anatomical surface area (Figs 1 and 2, B - D, D1 and A - C, C1). All measurements were done by the author.

The two measurements were added together and the total estimated size of the surface of the normal parotid gland was calculated as a normative value (Fig. 3). A bedside clinical grading system is proposed,

based on the size increase from the normative value (Table 1) (illustrated in Fig. 4).

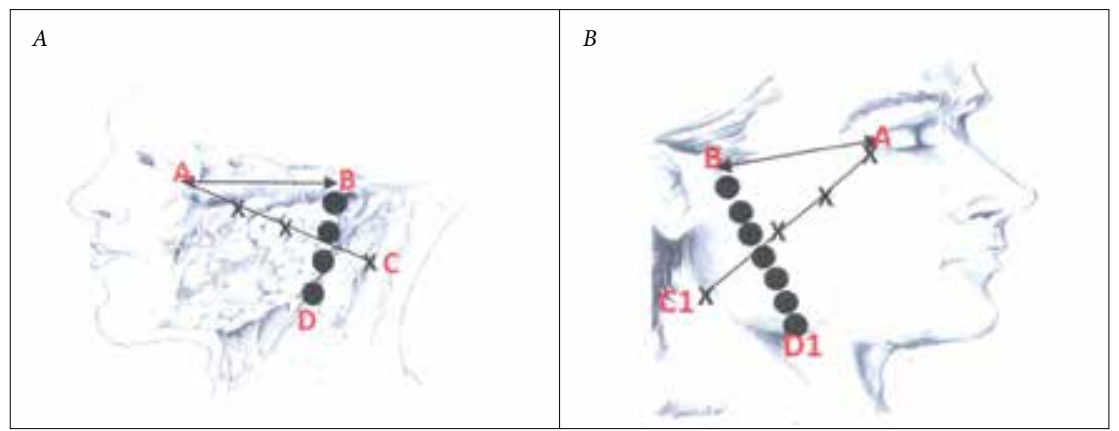

Fig 1. (A) Total surface area diameters of the normal adult parotid gland (oblique line A - C (lateral bone of eye socket to mastoid tip) + vertical line $B-D$ (root of helix to angle of mandible), in centimetres). (B) In an enlarged parotid gland, new points $C 1$ and $D 1$, extensions along $A-C$ and $B-D$ to the most distal palpable edges along the same lines ( $A-C+B-D$, in centimetres) give an estimation of the total palpable surface area diameters of the enlarged gland to offer a clinical grading system.

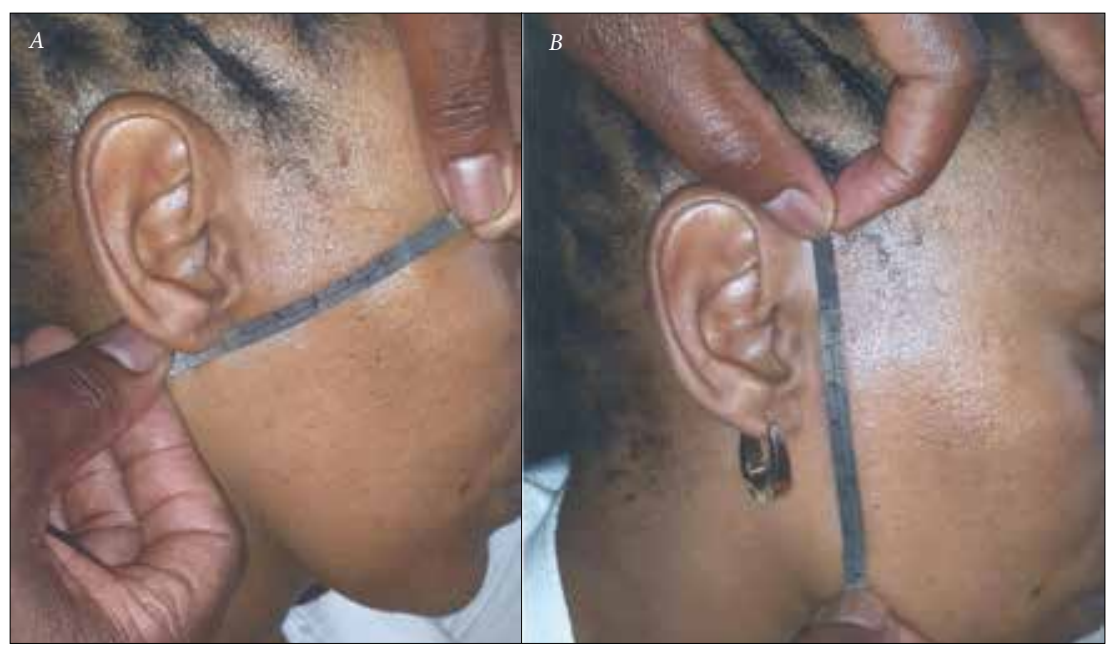

Fig. 2. Demonstration of bedside measurement of the parotid gland with a tape measure. Left: oblique line A - C; right: vertical line B - D. 


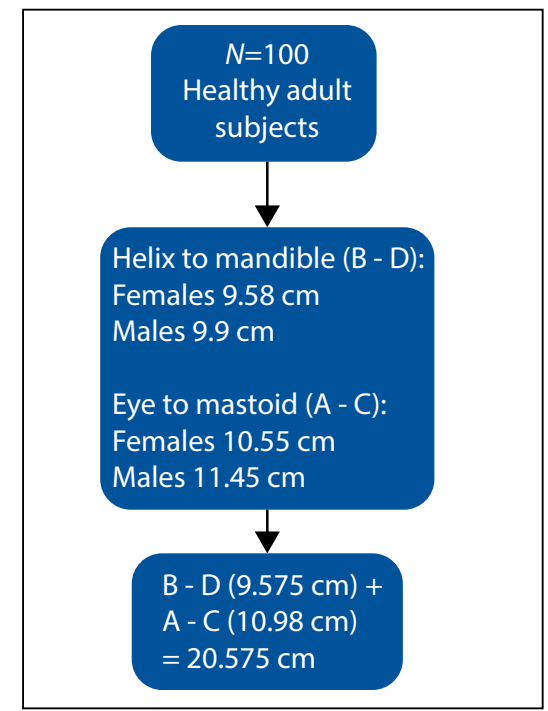

Fig. 3. Total estimated surface area diameters of the normal adult parotid gland (summation of the two measurements of vertical line $B-D$ and oblique line A - $C$, in centimetres). The normative value in this study for both males and females is $20.575 \mathrm{~cm}(21 \mathrm{~cm})$ surface area diameters.

Table 1. Proposed grading system for benign parotid gland enlargement

\begin{tabular}{lll}
\hline Clinical grade & Size increment above normative value $21 \mathrm{~cm}$ & Total \\
\hline Grade I & $2 \mathrm{~cm}$ & $21-23 \mathrm{~cm}$ \\
Grade II & $4 \mathrm{~cm}$ & $23-25 \mathrm{~cm}$ \\
Grade III & $6 \mathrm{~cm}$ & $25-27 \mathrm{~cm}$ \\
Grade IV & $8 \mathrm{~cm}$ & $27-29 \mathrm{~cm}$ \\
Grade V & $>9 \mathrm{~cm}$ & $>30 \mathrm{~cm}$
\end{tabular}

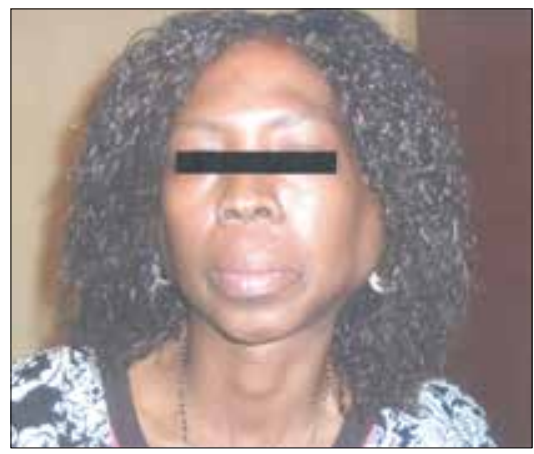

Fig. 4. The right parotid gland is grade III $(26 \mathrm{~cm})$ and the left is grade $V(33 \mathrm{~cm})$.
This grading system has revolutionised recording and communication of parotid gland enlargement in the ENT, head and neck and HIV/AIDS clinics at Steve Biko Academic Hospital, Pretoria, South Africa.

\section{Conclusion}

A bedside clinical system for grading of benign parotid gland enlargement is proposed. It is a scientific, easy, simple, repeatable and reliable way of communicating parotid gland size using a soft measuring tape.

Accepted 23 January 2015. 